\title{
NARRATIVAS DE VIDA: NORTEANDO AS PRÁTICAS LEITORAS NA EJA
}

\author{
Laudineia de Souza Sartore ${ }^{1}$ \\ Maria D’Ajuda Alomba Ribeiro ${ }^{2}$
}

\begin{abstract}
Resumo: Este artigo trata sobre a realização de uma pesquisa narrativa através da abordagem autobiográfica, no método histórias de vida, onde foram utilizadas entrevistas narrativas, em busca de variáveis que identificassem, através das histórias de vida desses alunos, como se configurou sua escolarização e o processo de apropriação da leitura. Foram realizadas entrevistas semiestruturadas a fim de compor as narrativas de vida. Utilizou-se para a coleta dos dados em campo o recurso de gravação em áudio. Foram entrevistados 10 alunos matriculados na EJA, tempo II, voluntários, acima de 18 anos. Após a decodificação dos dados, analisamos e refletimos sobre os processos formadores pelos quais passaram, procurando entender suas causas e consequências. Verificou-se como resultado que a experiência leitora da maioria dos alunos entrevistados foi deficitária antes e durante o processo escolar, permanecendo restrita, na maioria das vezes, a textos dos livros didáticos, ou seja, devido ao pouco acesso às leituras no decorrer dos estudos, tanto na escola como fora dela, esses alunos não adquiriram os conhecimentos necessários para fazer as inferências no processo de leitura, que levam à compresão leitora.
\end{abstract}

Palavras-chave: Compreensão leitora. Educação de jovens e adultos. Narrativas de vida. Pesquisa Narrativa.

\section{NARRATIVES OF LIFE: NORTEANDO PRACTICES READERS IN THE EJA}

\begin{abstract}
This article deals with the accomplishment of a narrative research through the autobiographical approach, in the method of life stories, where narrative interviews were used, in search of variables that identified, through the life histories of these students, how their schooling was configured and the process of appropriation of reading. Semi-structured interviews were conducted in order to compose life narratives. The audio recording feature was used for data collection in the field. We interviewed 10 students enrolled in the EJA, time II, volunteers, over 18 years. After decoding the data, we analyze and reflect on the formative processes they have gone through, trying to understand their causes and consequences. As a result, the reading experience
\end{abstract}

\footnotetext{
${ }^{1}$ Mestra em Letras pelo PROFLETRAS na UESC. Email: Idsartore@ hotmail.com.

2 Doutora em Linguística Aplicada pela Univ. de Alcalá, Pós-Doc em O ensino de PLE e a Comum. Intercultural no mundo dos negócios hispano, na mesma Universidade. Email: profdajuda@gmail.com.
} 
of the majority of the students interviewed was deficient before and during the school process, being restricted, in most cases, to textbooks, that is, due to the lack of access to the reading during the course of the studies, both at school and beyond, these students did not acquire the knowledge necessary to make the inferences in the reading process that lead to the reading comprehension.

Key words: Reading comprehension. Youth and adult education. Life narratives. Narrative Research.

\section{Introdução}

A pesquisa narrativa é retratada por alguns estudiosos, tais como Santos e Santos (2008), Abrahão (2011) e Benjamin (1994), como uma metodologia de investigação ou técnica de pesquisa social.

Segundo Santos e Santos (2008), a pesquisa narrativa, através da coleta de histórias de vida, pode ser considerada tanto como um método, como também uma técnica de pesquisa social utilizada pelos antropólogos, sociólogos, psicólogos, educadores e outros estudiosos, como coleta de informação para seus trabalhos. "Ela, enquanto método, utiliza-se das trajetórias pessoais no âmbito das relações humanas. Busca conhecer as informações contidas na vida pessoal de um ou de vários informantes, fornecendo uma riqueza de detalhes sobre o tema" (SANTOS e SANTOS, 2008, p. 715).

No que se refere à pesquisa Narrativa, Abrahão (2011, p. 9) afirma que "nesta tradição de pesquisa, o pesquisador não pretende estabelecer generalizações estatísticas, mas, sim, compreender o fenômeno em estudo, o que lhe pode até permitir uma generalização analítica", permitindo assim a comparação entre a vida estudantil dos alunos entrevistados, alguns aspectos pedagógicos de sua formação, principalmente no que tange ao seu processo de alfabetização e letramento nos anos iniciais de estudo, suas aprendizagens leitoras realizadas ao longo da vida.

Segundo Benjamin (1994), a pesquisa narrativa é um importante recurso para a produção de dados em uma pesquisa, dando oportunidade ao pesquisador de vivenciar e interpretar a realidade, procurando dar sentido às ações e aos pensamentos das personagens e interlocutores das narrativas. Dessa forma, trata-se de uma metodologia de investigação que tem sido muito 
utilizada para o desenvolvimento pessoal e profissional de professores com muito sucesso e, em menor proporção, com alunos, inclusive da EJA, vindo assim a contribuir de alguma forma para o seu desenvolvimento educacional:

No esforço de retomar a infância distante, a que já me referi, buscando a compreensão do meu ato de ler o mundo particular em que me movia, permitam-me repetir, recrio, revivo, no texto que escrevo, a experiência vivida no momento em que ainda não lia a palavra. E algo que me parece importante, no contexto geral de que venho falando, emerge agora insinuando a sua presença no corpo destas reflexões (FREIRE, 1989, p. 10).

Freire, na citação acima, fala da importância das memórias, da autobiografia, reviver a experiência vivida, aquilo que marcou seu momento de aquisição da leitura. Através dessas narrativas de vidas, podemos proporcionar esse reviver aos nossos participantes, onde os mesmos irão evocar suas experiências de leitura e, por sua vez, demarcar sinalizações da presença e/ou ausência de práticas leitoras, constantes ou não, em suas vidas. Conforme citado por Silva (2015a, p. 213), a utilização das entrevistas narrativas são importantes por possibilitarem que o sujeito, ou seja, o aluno entrevistado "se pense como parte integrante de uma história social que não é só sua. Identificando-se com as demais histórias".

O estudo desenvolvido procurou identificar, através das histórias de vida dos alunos da EJA, tempo II, como configurou-se sua escolarização e o processo de apropriação da leitura. Para tal, utilizou-se da pesquisa narrativa, cujos benefícios pode-se destacar, dentre outros, dar voz aos sujeitos participantes, construir historicamente a realidade desses alunos, levando-os a uma reflexão sobre a própria vida e seu processo de apropriação da leitura, dando aos educadores sinalizações que permita a elaboração de estratégias que contribuam para o desenvolvimento educacional do alunado da EJA.

Os sujeitos do estudo, então, foram alunos da modalidade Educação de Jovens e Adultos, tempo II, que corresponde ao ensino fundamental II da educação básica, regularmente matriculados em determinado colégio público, com idades acima de 18 anos, que se propuseram como voluntários, sendo oriundos das turmas do 6/7ㅇ e do 8 \% $/ 9^{\circ}$ anos da EJA.

Os educandos são oriundos dos diversos bairros da cidade, bem como da zona rural do município, e estão na faixa etária entre 09 e 50 anos de 
idade, em sua maioria, trabalhadores da zona rural, principalmente colheita de café e embaladores de mamão.

\section{Metodologia da pesquisa narrativa}

Como material empírico, foram recolhidas dez narrativas de vida desses alunos. Para não atrapalhar o andamento dos estudos dos alunos, as entrevistas foram realizadas em duas semanas disponibilizadas as avaliações do segundo semestre, no turno noturno, tendo em vista que nesse período eles são liberados mais cedo, assim que terminam a atividade.

Como recurso, para a coleta de dados em campo, utilizamos a gravação em áudio, que, conforme Santos e Santos (2008, p. 716), é imprescindível para que se validem os fatos estudados, haja vista que a utilização do gravador como recurso é bastante prático e fundamental para o método histórias de vida, porquanto, além de preservar e registrar todos os detalhes da fala dos depoentes, também permite que o entrevistador preste mais atenção ao depoimento cedido.

As entrevistas foram realizadas individualmente (pesquisador e aluno), semiestruturadas, seguindo um roteiro previamente estabelecido. Optamos por coletar os dados individualmente por que esse tipo de pesquisa, segundo Gibbs (2009), tende a ser rica em detalhes particulares e confidencialidades que necessitam de uma relação de confiança mútua e alguma intimidade, muito difícil de ser criada em grupos.

Todos os participantes demonstraram boa vontade durante a entrevista. No início ficaram um pouco inibidos, mas procurei usar uma linguagem fácil, demonstrando sempre interesse, acompanhando toda a narrativa, encorajando-os nos momentos adequados, deixando-os à vontade para que pudessem narrar suas histórias de vida, seus pensamentos, suas opiniões, sempre guiados pelas perguntas norteadoras.

Dos 10 entrevistados, apenas um era do sexo masculino e foi o que respondeu mais evasivamente, apesar de demonstrar que se lembrava de todo o passado, ao contrário de algumas das alunas entrevistadas que aparentavam muita dificuldade em buscar as lembranças.

As entrevistas foram direcionadas para o tema proposto, que é a leitura, através de algumas perguntas abertas, de modo a encorajar o entrevistado a relatar fatos referentes ao objeto da pesquisa, de acordo com as 
categorias, previamente selecionadas: Lembranças espaçotemporais ${ }^{3}$, Entrada no mundo letrado, Mediadores, Recursos materiais, Recordações de fatos marcantes, Fazendo uma reflexão, Verificando a gostatividade pela leitura.

As gravações em áudio, dessas narrativas de vida, constituem o corpus de nossa pesquisa. Para análise e interpretação desses dados utilizamos a "Análise Temática", que consiste em reportar em cada relato de vida as passagens concernentes ao tema, com o objetivo de comparar, depois, os conteúdos dessas passagens de um relato a outro (SANTOS e SANTOS, 2008, p. 716).

\section{Análise dos dados da pesquisa}

O primeiro passo da análise de dados da pesquisa foi a transcrição das entrevistas que, conforme Santos e Santos (2008, p. 716), trata-se de uma tarefa árdua que demanda tempo, mesmo para um pesquisador experiente na técnica, havendo a necessidade de escutar as gravações diversas vezes.

As falas não passaram pelo processo de arrumação, foram transcritas da mesma forma como estão nos áudios, apesar de que esse processo facilitaria a leitura e análise das transcrições, entretanto, conforme Gibbs (2009), perderia a sensação de como os correspondentes estavam se expressando, e esse detalhe é de suma importância para o estudo realizado.

Os nomes das pessoas entrevistadas foram colocados no início de cada fala, em letra maiúscula, de forma constante e correta, a fim de facilitar a busca eletrônica na fase de análise. Para garantir a confidencialidade, após as transcrições, salvou-se outro arquivo para a realização das análises, no qual se utilizou a anonimação dos nomes, os quais passaram a denominar-se: DAIL, ANCI, ALVA, ENI, INE, CIDA, IENE, ISA, ANA e ONE. Para formar os codinomes empregou-se a estratégia de junção de algumas letras que formam o nome próprio do entrevistado.

Após a transcrição dos dados, iniciou-se o processo de análise das transcrições, realizando-se, primeiramente, uma "Leitura Flutuante", com a leitura e releitura dos dados até que se tornassem mais precisos, sempre destacando os pontos relevantes.

\footnotetext{
${ }^{3}$ Para essa categoria foram selecionados alguns questionamentos referentes à infância dos entrevistados, antes de adentrar à escola e durante os primeiros anos escolares.
} 
A “leitura flutuante", segundo Santos e Santos (2008, p. 717), consiste em:

\begin{abstract}
Estabelecer contato com os documentos a analisar e em conhecer o texto deixando-se invadir por impressões e orientações. [...] Pouco a pouco a leitura vai se tornando mais precisa, em função de hipóteses emergentes, da projeção de teorias adaptadas sobre o material e da possível aplicação de técnicas utilizadas sobre materiais análogos.
\end{abstract}

Durante a leitura e releitura das narrativas transcritas (em que os conteúdos dos áudios das entrevistas transformaram-se em escritos, mantendo a fidelidade do que foi dito) empregamos o processo de "Codificação", onde foram selecionadas as categorias mais marcantes das narrativas, buscando informações e significados pertinentes nela contidos, fazendo, conforme orientado por Santos e Santos (2008), a "Marcação de partes consideradas importantes para atingir os objetivos da pesquisa".

Nessa fase da análise, realizou-se uma ação conjunta entre leitura das transcrições e audições dos áudios das entrevistas, a fim de que os sentidos das transcrições tornassem-se mais claros, evitando-se erros de interpretação, seguindo as orientações de Gibbs (2009, p. 28), ao afirmar que ouvir a voz torna o sentido mais claro e até sugere diferentes interpretações, visto que a maioria das transcrições só capta os aspectos falados da entrevista e não reflete o ambiente, o contexto, a linguagem corporal e a sensação geral da sessão.

Seguindo as orientações de Santos e Santos (2008) para sinalizar as categorias nas narrativas transcritas, utilizou-se marcadores de textos de cores diferentes, nas quais, as partes que demonstraram alguma aproximação entre si foram grifadas da mesma cor, inclusive entre uma narrativa e outra, procedendo assim ao "Esboço Analítico", a partir do qual se elaborou "Quadros Demonstrativos" por categorias analisadas.

\title{
Resultados da pesquisa por categorias
}

Durante o processo de codificação, seguiram-se as orientações de Gibbs (2009) efetuando-se uma comparação sistemática, que consiste em fazer uma série de perguntas hipotéticas para explorar todas as dimensões 
dos fenômenos em estudo, no caso, as entrevistas codificadas, obtendo-se os resultados por categorias.

\section{Categoria: Lembranças espaçotemporais ${ }^{4}$}

De todos os entrevistados, apenas dois declararam que tinham contato com livros antes de entrar no mundo letrado. Depois de entrar no mundo letrado, ou seja, ir para a escola aprender a ler, a maioria deles só teve contato com livros didáticos. Poucos tiveram a oportunidade de manusear textos de diferentes gêneros.

Em relação à contação de histórias, apenas quatro dos participantes declararam terem acesso antes de entrarem no mundo letrado, e a figura predominante nas contações foram vizinhos. Apenas uma entrevistada, de nome fictício Ana, declarou que a mãe lia e contava histórias para ela, tendo inclusive lhe ensinado as primeiras letras. A entrevistada Ana está com 30 anos de idade e ainda gosta de ler histórias de fantasias, corroborando com Torres e Tettamanzy $(2008$, p. 3) para as quais as histórias agradam a todos sem fazer distinção de idade, classe social ou circunstância de vida.

A contação de histórias, além de proporcionar o resgate da memória e o estímulo à imaginação e à criatividade, também é muito utilizada como estratégia pedagógica na educação infantil e ensino fundamental, ou seja, trata-se de uma peça chave para o aprendizado, à qual poucos dos entrevistados tiveram acesso.

Segundo Torres e Tettamanzy (2008, p. 3), a contação de histórias não serve apenas para divertir ou estimular a imaginação como também para educar, instruir, desenvolver o raciocínio, ser ponto de partida para o ensino de conteúdos programáticos, motivar para o aprendizado, dentre outros. Nesse caso, a criança que ouve histórias desde cedo terá mais facilidade com a aprendizagem da leitura e irá acumulando conhecimentos que poderá servir como conhecimentos prévios necessários à compreensão leitora. Dessa

\footnotetext{
${ }^{4}$ Para essa categoria foram realizados os seguintes questionamentos aos entrevistados: Conte-me sobre sua infância, seu contato com a leitura, como textos, livros, antes de ir efetivamente a uma escola? Como foi seu primeiro ano na escola? Havia contato com livros, textos, leituras? Contações de histórias? Onde, como, quando aprendeu a ler? Havia textos, livros?
} 
forma, a presença da contação de histórias é um caminho que leva o indivíduo a tomar gosto pela leitura.

Dos quatro entrevistados que declararam que havia contação de histórias na sua infância, apenas um, o Dail, declarou não gostar de ler. Entretanto, ele pratica leitura no celular, lendo notícias da atualidade brasileira, ou seja, não se encontra alheio à leitura, apesar da declaração. Todos os entrevistados que tiveram acesso a contação de histórias na infância praticam a leitura de textos, atualmente.

A maioria demorou no processo de aquisição da leitura, como por exemplo, a aluna Eni que começou a estudar com 13 anos em uma escola multisseriada e só adquiriu a leitura aos 20 anos de idade, depois de passar um grande período fora da escola, tendo inclusive passado por alguns vexames, por ter voltado a estudar no turno matutino em uma turma de crianças, como foi o caso da entrevistada Eni: "Ah, foi muito vergonhoso, que eu estudei durante o dia (risadas)".

Através das perguntas norteadoras dessa categoria foi possível verificar que a entrada no mundo letrado não foi fácil para a maioria dos participantes como podemos constatar em alguns relatos abaixo, das entrevistadas Alva, Eni e Iene:

Eu me lembro que antes de ir para escola era feito frase tipo aquele negócio de juntar as palavras pato, mesa, entendeu? [...] Em casa. Eu aprendi assim aí depois fui participando de uma escolinha na roça, porque eu morava não roça, e depois fui participando de uma escolinha na roça e atualizando mais até juntar as letras pra soletrar, aí dai pra cá (ALVA).

Eu era uma menina muito pequena e ficava em casa com a minha mãe e como meu pai era falecido eu quase não tive oportunidade de ir pra escola porque eu ficava com minha mãe, ela morava na roça. [...] A morte dele me deixou muito abalada. Daí a minha mãe morava na roça então era muito distante pra gente ir pra escola (ENI).

Antes, tipo não tinha muita convivência assim porque, na minha infância eu passei muita necessidade não tem. Aí tipo eu comecei a ir para escola tarde então no caso eu comecei a estudar com meus 10 pra 11 anos por ai. Ai eu não tive muita coisa assim, mas eu tinha vontade de aprender ler (IENE). 
As três entrevistadas, dos relatos acima, começaram a estudar acima da idade compatível. Alva (39 anos) começou a estudar tarde por causa da dificuldade de acesso à escola, morava na zona rural e não havia transporte escolar, mais adiante necessitou parar seus estudos por carência financeira, precisou trabalhar para ajudar a família.

Eni (27 anos) também morava na zona rural e havia dificuldades de acesso à escola, por isso começou a estudar tarde. Com muita dificuldade de aprendizado, talvez em decorrências de traumas de infância, pela perda do pai, conforme relata a própria entrevistada, que ao tocar no assunto os olhos ficam marejados de lágrimas, abandonou a escola por vergonha em virtude de que não conseguia aprender a leitura. Retornou aos 20 anos de idade e após aprender a fazer o próprio nome pensou: "não vou pra escola mais não, se eu não aprendi quando eu era pequena, depois de grande eu não vou aprender (risadas)" (ENI). Atualmente, voltou a estudar, com muito sacrifício, pois possui uma filha e não tem com quem deixar para frequentar a escola no turno noturno.

De acordo com Leite (2013, p. 178), o sucesso ou o fracasso da aprendizagem tem implicações claras na autoestima do aluno, entendida como os sentimentos derivados da avaliação que o indivíduo faz de si mesmo.

Iene (19 anos) era moradora da zona rural e também não tinha acesso à escola e começou a estudar tarde. Nessa época havia o escolar, mas as estradas eram intransitáveis e quase sempre o carro não conseguia buscar os alunos, o que gerava muitas faltas. Só conseguiu estudar porque os moradores improvisaram uma escolinha multisseriada na localidade onde ela morava.

A minha primeira escola foi lá, foi lá na roça. Tinha uma escolinha lá. Não tinha escola, aí juntou os professores e pegou e fez tipo uma casa aí fez tipo uma escolinha lá, uma escola. Aí depois, acho que, acabou lá. Aí eu tive que vir estudar aqui em Itabela. Ai escolar ia pegar a gente quase todos os dias lá para a escola, mas ai, às vezes, chovia muito, então não entrava carro nenhum lá, a gente ia e faltava a escola (IENE).

Todos os entrevistados enfrentaram dificuldades para conseguir estudar, alguns, logo no início da escolarização, outros mais adiante. Hoje, ainda enfrentam muitas lutas para conseguirem conciliar trabalho e estudos, 
muitas vezes chegam atrasados à escola. Sentem falta da merenda, quando não tem, já que, muitas vezes, não dá tempo se alimentarem antes de ir para a escola, bem como, costumam perder a primeira aula em decorrência da incompatibilidade de horários da saída do trabalho com a chegada à escola.

Todos os enfrentamentos, as lutas pelas quais passaram e passam, levam ao truncamento no processo de aprendizagem, pois, pelos relatos apresentados, verifica-se que não houve um processo de aquisição da leitura, de forma contínua, passo a passo, outrossim, rupturas no meio do processo, o que de alguma forma veio a prejudicá-los nos estudos, inclusive na aquisição da leitura, principalmente em relação à compreensão textual, conforme declarações dos mesmos.

\section{Categoria: Entrada no mundo letrado 5}

Em nenhuma das entrevistas apresentadas foi detectada a presença da utilização de estratégias leitoras na metodologia utilizada pelo professor para ensinar a leitura, pois, conforme os relatos infere-se que a maioria dos professores tomava a leitura sem levar em conta os conhecimentos prévios dos alunos, não havia uma preparação para iniciar a leitura, tais como a motivação, objetivos da leitura, estabelecer previsões sobre o texto, promover as perguntas dos alunos sobre o texto, que são algumas das estratégias propostas por Solé para antes da leitura.

Também não foram detectadas estratégias utilizadas durante a leitura. Quanto às estratégias depois da leitura, apenas em um relato, da participante Anci, percebe-se a presença de uma das estratégias, que pode ser utilizadas, tanto durante, quanto após a leitura, o resumo:

Tinha aula de leitura, as professoras sempre tinha um dia na semana que levava todos os alunos para sala, a outra Sala de Leitura, e mandava a gente sempre escolher um livro e levar para casa para ler, aí na outra semana a gente voltava e tinha que ler o que a gente o resumo do que a gente entendeu. E também tinha sempre um caderno, uma pasta, era uma pasta que tinha um caderno com um livro ai todo toda semana também sempre tinha um

\footnotetext{
${ }^{5}$ Durante a entrevista os questionamentos referentes a essa categoria foram: Como era seu professor? Como ele trabalhava a leitura em sala de aula?
} 
colega que levava. Aí era sempre misturada toda semana um levava, outra semana outro levava ai a gente escrevia o resumo do que a gente entendeu no livro também (ANCI).

Segundo Souza e Bernardino (2011), a iniciação literária, desde a infância, com livros de imagens, com ou sem textos, e o trabalho com contos, podem ser uma grande alavanca na aquisição da leitura para além da simples decodificação do código linguístico. Sendo assim, ainda conforme o autor, o planejamento curricular do professor deve levar em conta a presença da leitura, formando crianças que gostem de ler e escrever.

Analisando as narrativas de vida, percebe-se que a minoria dos entrevistados teve uma vida estudantil ativa em relação à leitura. Em seus relatos, presenciam-se atividades muito tradicionais, sem a presença do lúdico, tais como brincadeiras, cantigas, jogos, contação de histórias, bem como o recontar a história pelo aluno, que é também uma atividade muito importante.

Como exceção, temos os relatos de 03 alunas: Anci, cuja professora ensinava com utilizando música e contação de histórias; a de Cida contava histórias; e a de Ana, que pode ser considerada a que mais adequa-se como mediadora do ensino, pois utilizava diversas atividades lúdicas para ensinar, inclusive as contações de histórias, brinquedos e brincadeiras.

\section{Categoria: Mediadores e Recursos materiais ${ }^{6}$}

Dos dez alunos entrevistados, cinco declararam terem sido incentivados à leitura por outras pessoas ou situações, além da professora em sala de aula. Sendo que, dentre essas pessoas, vizinhas, avós, tios e irmãos, nota-se a ausência do apoio familiar, paternos e maternos, representados por pais e mães, em relação a quase todos os entrevistados.

Apenas uma das entrevistadas relatou a presença da mãe na escola, procurando saber da vida estudantil da criança, que se mostrava feliz, já que a professora só tecia elogios à sua pessoa. Geralmente, a presença constante

${ }^{6}$ Questionamentos: Você foi incentivado a ler por outras pessoas ou situações? Que materiais eram utilizados para leitura? Livros? Textos? 
dos pais na escola leva a um bom comportamento do aluno e a um maior interesse pelos estudos.

Segundo Polonia e Dessen (2005, p. 305), a aprendizagem do aluno só é evidenciada quando este é cercado de atenção da família e da comunidade, que devem ser orientadas pela escola sobre as abordagens metodológicas utilizadas no ensino, para que possam acompanhar o progresso e as necessidades do aluno.

Os alunos entrevistados não tiveram acesso a esses projetos, pois em sua fase de estudos, quando criança, na maioria das vezes, o único material didático disponível era uma cartilha, para todos, que ficava disponível apenas ao professor. "Só professora que tinha a dela". [...] "Que todo mundo só lia lá né. Depois ela ia e guardava lá mesmo”. [...] “Ela ia chamando cada um pra ir lá na mesa, outra hora vinha na nossa mesa fazer a leitura" (ANA).

Monteiro e Santos (2013) relatam sobre a importância dos recursos e da família para o desenvolvimento infantil, em todos os sentidos, inclusive no aprendizado da leitura, em especial, à compreensão leitora. Os autores esclarecem que a disponibilidade de livros, jornais, revistas e brinquedos agem como promotores da evolução leitora, que leva à compreensão, entendida como processo resultante da interação de pistas contextuais e conhecimento prévio, o que nos remete às estratégias de leitura.

Monteiro e Santos (2013) também discorrem sobre a família, como fonte de estímulos para a aquisição de novos conhecimentos, possibilitando o armazenamento de informações, instruções e aprendizagens, que serão necessárias para a compreensão de leitura.

Deduz-se, a partir dos relatos nas entrevistas, que esse acompanhamento familiar não ocorreu no processo de aquisição da leitura, da maioria dos alunos entrevistados, com exceção das alunas Anci, Ana e Alva, cujos relatos mostram a presença das mães, interagindo com o aprendizado escolar: "Quem sempre lia pra mim era a minha mãe, e me ensinava também às letrinhas" (ANA).

Tive, eu minha mãe me botou no reforço, no colégio, eu estudava de manhã normal e a tarde tinha o reforço e aí depois eu sai do colégio, sai do colégio não, eu estudei de manhã e à tarde minha mãe me colocou no projeto. Esses projetos de criança pra aprender outras coisas, não tem? Para não ficar na rua eu era muito rueira também (ANCI). 

compreensão do texto devem ser trabalhadas desde a infância, tanto na escola como no ambiente familiar, e, para tal, os recursos são muito importantes, tendo em vista que a criança inserida em um contexto cultural rico e diversificado, com a disponibilidade dos pais em oferecer recursos materiais e diferentes suportes, levam a criança a aprender com mais facilidade e apresentar melhor desempenho escolar (MONTEIRO e SANTOS, 2013).

Todos os entrevistados tiveram seu percurso escolar, desde a infância até o momento, em escolas públicas, nas quais, pelos relatos da maioria, não eram disponibilizados recursos materiais diversificados a fim de favorecer o aprendizado dos alunos, bem como, as famílias não possuíam recursos para disponibilizar esses materiais em seus lares, com exceção da Ana, que teve acesso, em sala de aula, a alguns brinquedos, mas não da escola, e sim, providenciados pela professora.

\section{Categoria: Recordações de fatos marcantes ${ }^{7}$}

O entrevistado Dail foi o único que declarou não se lembrar de nenhum fato marcante em relação ao seu contato com a leitura. Ele também foi o que se mostrou mais evasivo durante toda entrevista. Na maioria das vezes, respondia com monossílabos: "Não que eu lembro, tenho muita lembrança não. Daqui pra lá aconteceu muita coisa" (DAIL).

Recordações de fatos marcantes envolvem a dimensão afetiva, as emoções, que, para Cosenza (2011), é o que mobiliza os recursos cognitivos responsáveis pela atenção e percepção. Ainda conforme o autor, as emoções originam-se no cérebro e produzem a dopamina, responsável pelo prazer e bem estar que levam à motivação, a um sentimento de recompensa que favorece a aprendizagem, perpassando também pelo hipocampo e pela memória.

Segundo o autor, as emoções podem ser positivas ou negativas. Quando positivas, ativam os desafios, as curiosidades, o entusiasmo, a alegria,

${ }^{7}$ Que outras lembranças você traz no decorrer dos anos em relação ao seu contato com a leitura? Com os livros, os textos? 
favorecendo ao aprendizado, mas, quando negativas, perturbam a aprendizagem através de sentimentos que podem ser de raiva, medo, tristeza, stress, desprezo, dentre outros.

Durante a entrevista de Eni, analisamos dois momentos relatados que descrevem situações que levaram a fortes emoções. Na sua infância, a morte do pai foi relatada por ela com lábios lacrimejantes, lábios trêmulos, olhar perdido. Ainda hoje essa recordação lhe traz sofrimento: "Foi uma infância dura”. [...] “Eu fiquei com um pouco de trauma nesse período”. [...] “A morte dele me deixou muito abalada. Daí a minha mãe morava na roça então era muito distante pra gente ir pra escola" (ENI).

Uma aluna marcada pela ausência paterna, de uma forma trágica, com dificuldades de acesso ao ambiente escolar, por residir na zona rural, muita dificuldade de aprendizagem não tratada por profissionais habilitados. Dificuldades que, ainda hoje, mostram-se presentes na vida estudantil da aluna, que aprendeu a assinar o próprio nome com 20 anos de idade.

Já adulta, através das críticas que recebia do marido por não saber a leitura, apesar de machucarem muito emocionalmente, também serviram de impulso para que ela voltasse a interessar-se pelos estudos, a fim de provar que também possuía capacidade.

Então, ali, naquela convivência em que eu vivia, eu sentia
vontade de, de entrar na escola, de aprender alguma coisa
para minha vida. Mas aí o tempo passou e devido a muitas
brigas que a gente teve, eu fiquei muito envergonhada,
por algumas palavras assim negativas. Ai eu decidi
separar, vir pra cidade e estudar, ai retornei (ENI).

As emoções que, conforme Cosenza (2011), são comandadas pelo sistema nervoso, levaram à raiva, à tristeza, mas também a colocaram em um estado de alerta. Agora, Eni faz questão de aprender e já está juntando uma poupança para ingressar em uma faculdade, sonho que alimenta em secreto.

Outra entrevistada, a Iene, também teve uma infância difícil cercada por dificuldades financeiras que a obrigou a trabalhar ainda criança para ajudar os pais. $\mathrm{O}$ acesso à escola também foi outro empecilho para seus estudos. Mostra-se muito grata à sua primeira professora:

Essa professora que me ensinou a ler, me ajudou muito, tipo que eu não tive uma infância que nem todas as crianças têm, de ter tudo na hora que quiser e tal. A gente 
tinha que trabalhar também, eu estudava e trabalhava. Que minha mãe não tem muitas condições, nem meu pai, naquela época né? Hoje a gente tem uma condição melhor. Então aí ela me ajudou muito nesse período, ela me ajudou muito (IENE).

A maioria dos estudantes entrevistados eram moradores da zona rural na infância e passaram por muitas dificuldades que atrapalharam o desenvolvimento das atividades escolares, como, por exemplo, a falta de acesso ao ambiente escolar, ocasionada por falta de escolas do campo, de transporte, estradas adequadas, dentre outras.

\section{Categoria: Fazendo uma reflexão ${ }^{8}$}

Dos dez alunos entrevistados, oito declararam possuir dificuldades na leitura e interpretação de texto e apenas dois disseram não possuir dificuldades, entretanto, quando indagados com mais detalhes, percebe-se que a compreensão ainda não é alcançada integralmente, com grande facilidade. Não foi feito diagnóstico que comprovasse que esses alunos, realmente, não apresentam dificuldades na leitura.

As dificuldades declaradas podem ter variadas causas, ou conjunto delas, como: traumas emocionais vividos na infância, a falta de apoio dos pais, recursos materiais insuficientes, deficiências metodológicas por parte do professor, dificuldades de acesso ao ambiente escolar, gravidez na adolescência, desmotivação, dentre outros, que os levaram a vivenciaram poucas experiências de leitura em seus anos iniciais de estudo, escolares e extraescolares, bem como nos anos seguintes, de acordo com os relatos de suas narrativas de vida.

Snowling e Hulme (2013, P. 177) referem-se às variâncias em fatores críticos, que podem ocasionar maus leitores, dentre eles, a qualidade da instrução recebida pela criança, a frequente mudança de escola e a frequência escolar, dentre outras.

Todos os alunos entrevistados sofreram essas variâncias, tendo em vista declararem problemas em relação à frequência escolar e, a maioria, não teve a oportunidade de uma instrução de qualidade, onde pudessem ter acesso

\footnotetext{
${ }^{8}$ Questionamento: Fazendo uma análise de si mesmo, você sente alguma dificuldade na leitura?
} 
a diferentes tipos de textos, em diferentes gêneros. O contato com a leitura mostrou-se muito deficitário.

\section{Categoria: Verificando a gostatividade ${ }^{9}$ pela leitura}

Segundo Freire (1996, p. 67), no que se refere à gostatividade, existe uma relação entre o gosto e a prática, em todos os aspectos, aos quais podemos incluir a leitura: "Não posso desgostar do que faço sob pena de não fazê-lo bem".

Analisando essa categoria verificamos que dos dez alunos entrevistados, sete gostam de ler e três não gostam, sendo que, os que não gostam leem apenas os textos necessários quando instruídos pelos professores, com exceção de um aluno, que apesar de declarar não gostar de ler, vem treinando a leitura no celular, lendo notícias, atualidades do país, o Dail (fala no quadro 7, acima).

A análise dessa categoria também veio a demonstrar as práticas de leitura dos entrevistados, cujo conhecimento por parte do professor é muito importante, dados que permitem a ele repensar seus materiais de leitura utilizados em sala de aula, a fim de adequá-los às preferências de seu alunado.

Dos alunos, que gostam de ler, foram detectados alguns gêneros textuais, tais como, o romance, a poesia, as histórias em quadrinho, os textos bíblicos, os contos de fadas, as histórias verídicas e as notícias. "Romance, gosto de ler romance, de vez em quando eu leio romance" (ALVA).

De acordo com Sabino (2008), a partir dos seis meses de idade, os familiares devem promover na criança o gosto pela leitura oferecendo livros adequados à sua faixa etária e na escola, assim como, os professores, de todas as disciplinas, devem continuar a desenvolver estratégias adequadas objetivando criar a necessidade de ler.

Percebe-se que os alunos, atualmente, estão mais antenados às novas tecnologias, pois todos os entrevistados possuem whatsapp e alguns só

\footnotetext{
${ }^{9}$ Termo utilizado por Nair Floresta Andrade Neta, pioneira no estudo da gostatividade como fenômeno afetivo emergente. Trata-se, segundo a autora, de uma reação emocional não intencional, de origem inconsciente, que se manifesta através da aprendizagem, durante o desenvolvimento individual (ANDRADE NET, 2011, p. 246).
} 
praticam a leitura nesses aplicativos, como é o caso do Dail, citado anteriormente, que gosta de ler notícias no celular.

De acordo com Moran (2000), o acesso às redes eletrônicas também estimula a busca on-line da informação desejada e é uma situação nova no aprendizado. O ponto negativo dessa situação é que o livro torna-se, cada vez mais, uma opção menos atraente.

A entrevistada Anci (24 anos) é outro exemplo de aluna que está sintonizada com as novas tecnologias, entretanto, conforme relato, só utiliza o whatsapp para troca de mensagens e odeia quando enviam textos grandes, os quais não leem, de forma alguma.

Muito difícil, na verdade (risada) eu fico mais focada no telefonei né inventei esse negócio de whatsapp, eu fico mais focada no telefone. [...] Só para você ter noção eu tenho maior raiva quando alguém me manda um texto desse tamanho pra mim ler eu só abro por abrir, mas não leio (ANCI).

Esse relato leva-nos a afirmativa de Moran (2000, p. 22): “Tornamonos cada vez mais dependentes do sensorial. Isso é interessante, mas muitos não partem do sensorial para voos mais ricos, abertos, inovadores".

Dos 10 relatos, apenas 02 usam a internet para leitura de textos, um para notícias e outro para histórias da vida real. Os outros a utilizam apenas para navegar nas redes sociais, como facebook whatsapp.

\section{Categoria: Estratégia de leitura}

Acrescentamos a categoria Estratégias de leitura, detectada no decorrer dos relatos, não como algo que esteja sendo ensinado pelos professores atuais dos alunos entrevistados, mas como algo que alguns deles fazem de forma natural, não se dando conta que estão utilizando uma estratégia para melhorar a compreensão leitora, como é o caso da aluna ALVA, ao utilizar a estratégia da releitura: "Sinto, às vezes sinto dificuldade, às vezes eu leio e não entendo, tenho que está lendo, relendo para compreender aquilo".

De acordo com Silveira (2005, p. 17), as estratégias de leitura são construtos de grande relevância, principalmente do ponto de vista da aplicação ou intervenção pedagógica. A autora afirma ainda que: 


\begin{abstract}
O papel das estratégias na leitura deve ser um dos pontos cruciais merecedores de atenção especial daqueles que desejam adquirir uma fundamentação mais substancial para uma intervenção pedagógica mais segura. Há muitas evidencias de que uma das grandes diferenças entre o leitor imaturo ou deficiente e o leitor maduro ou proficiente esteja justamente no uso eficaz que o segundo faz dessas estratégias, através de um controle consciente da compreensão do material que lê (SILVEIRA, 2005, p. 21).
\end{abstract}

Através dos dados coletados percebemos que a maioria dos professores pelos quais os entrevistados passaram não ensinaram as estratégias de leitura, não utilizaram e nem utilizam conscientemente, antes, durante ou após a leitura. O resumo é utilizado como uma metodologia de trabalho, na maioria das vezes, como atividade avaliativa, sem que o aluno saiba que através desse resumo ele pode melhorar sua compreensão do texto.

\title{
Categoria: Distorção idade/série
}

Dentre os alunos entrevistados, a desmotivação foi a que mais se destacou como causa da evasão escolar, e a dificuldade de acesso à escola como a causa do acesso tardio a escola.

As causas dessa "desmotivação" não foram detectadas nos relatos das entrevistas. Vários podem ter sido os motivos que levaram esses alunos a essa falta de interesse pelos estudos;

Antes teve um período, quando eu estava aprendendo que eu gostava. Não aguentava ver uma letra que eu tinha que ler. Ai depois fui desleixando. Agora que eu voltei a estudar, eu gosto de ler, gostei de ler. Ainda assisto os filmes legendado pra mim ir praticando as pontuações, as vírgulas e assim sucessivamente (ALVA).

Para evitar, ao menos parcialmente, essas ocorrências, cabe ao professor buscar meios para manter o interesse do alunado, com aulas motivadoras, interessantes e, uma boa opção, segundo Moran (2000, p. 53), seria a internet, que motiva pela novidade e pelas possibilidades inesgotáveis de pesquisa que oferece. 
Nenhum dos entrevistados declarou ter tido aulas utilizando internet ou quaisquer outras mídias da atualidade. Apenas uma entrevistada teve histórias, em vídeos, passadas em sala de aula pela professora.

No que tange ao retorno dos alunos à escola, Leite (2013, p. 148) afirma que o adulto não retorna à escola com a intenção de recuperar o tempo perdido ou para aprender algo que não aprendeu quando criança. O que ele busca é um aprendizado para as suas necessidades atuais.

Porque eu era danada demais (risadas), não gostava muito de escola não. Aí eu começava a estudar bem, no final do ano eu parava, na metade do ano. Não tinha paciência pra estudar não (INE).

Agora eu senti, agora senti o peso da consciência. [...] Hoje tá mais, hoje pra você conseguir um emprego você tem que ter, ter o que, o segundo grau completo né? Aí, está difícil conseguir um emprego (INE).

Todos os relatos demonstraram que a principal causa declarada para o retorno dos alunos evadidos foi a necessidade de capacitação para o trabalho. E todos tiveram alguém, da família ou amigos, incentivando-os a voltar aos estudos.

\section{Discussão geral dos resultados}

Figura 1 - Gráfico resumo

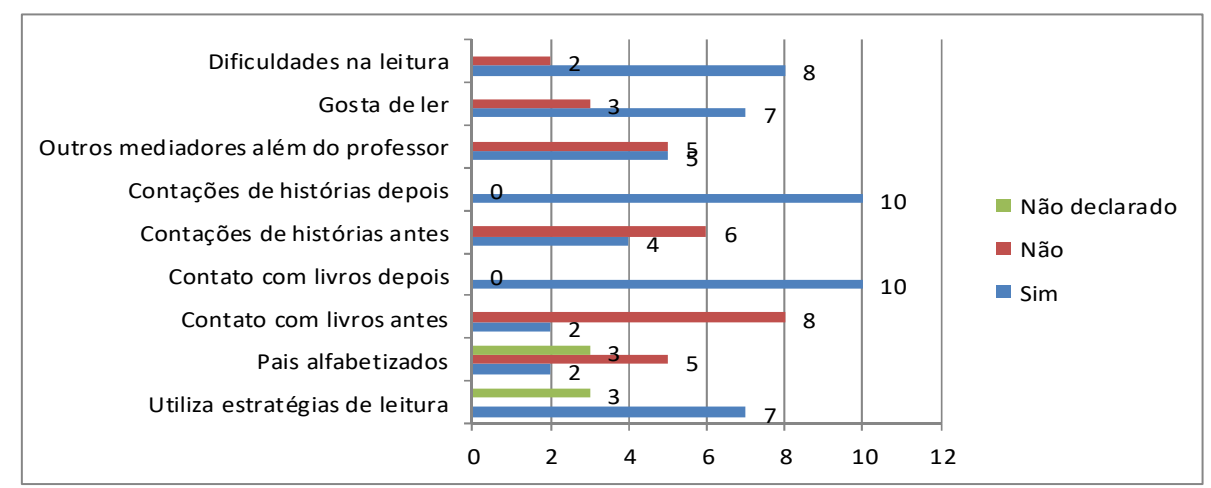

Fonte: pesquisa de dados.

Conforme elucidado no gráfico da "figura 1", elaborado com base nos dados coletados através das entrevistas narrativas, apenas 2 entrevistados 
disseram não terem dificuldades em leitura e compreensão de texto. Os outros 8 afirmaram, categoricamente, apresentarem dificuldades em práticas de leitura e compreensão textual:

"Eu tenho dificuldade". [...] "Para eu pegar a leitura, saber a vírgula, o ponto de interrogação, onde você pode parar para continuar" (INE).

"Sinto, às vezes sinto dificuldade, às vezes eu leio e não entendo, tenho que está lendo, relendo para compreender aquilo" (ALVA).

A participante de nome fictício Iene declarou não apresentar dificuldades de leitura e possui um histórico em que começou a estudar muito tarde, com 11 anos de idade, por morar na zona rural, não possuir escola no local onde residia e nem transporte para levá-la à escola mais próxima.

Seus pais eram analfabetos, como o eram os da maioria dos entrevistados, entretanto, sua imaginação e gostatividade pela leitura foram ativadas por uma vizinha que lhe contava histórias de conto de fadas, conforme relato da aluna: "Só a minha vizinha que contava história pra nós, história assim, tipo de conto de fadas pra nós quando eu era mais pequena, ai ficava imaginando como seria se eu soubesse ler" (IENE). Essa aluna sempre utiliza como estratégia para melhorar sua compreensão leitora a releitura e o resumo dos textos lidos.

O segundo participante que declarou não apresentar dificuldades na leitura, de nome fictício Cida, também possuía pais analfabetos, mas quando começou a estudar foi muito motivada pelo carinho de sua professora, da qual recebia muitos elogios, e os pais, apesar de não saberem a leitura, eram muito participativos na vida escolar da aluna, conforme relato na entrevista: "Ah, foi bom, nunca fiquei reprovada. Sempre tinha elogio das professoras, minha mãe sempre ia lá né, pra poder saber como eu tava indo, e eu sempre tava indo bem" (CIDA).

Segundo o relato, a leitura era constante, além de que a professora utilizava como metodologias de ensino atividades lúdicas tais como brincadeiras, jogos e contações de histórias.

A evasão escolar ocorreu visto que ela se casou e engravidou, mas agora que retornou aos estudos quer recuperar o "tempo perdido", conforme palavras da própria aluna: “Ah, eu acho que o tempo perdido que eu deixei para trás" [...] "Porque sem estudo você não é nada" (CIDA). A aluna utiliza, quando não está conseguindo compreender um texto, a releitura de textos, mas sem consciência de que está utilizando uma estratégia de leitura. 
A maioria dos entrevistados declara ter parado seus estudos por desmotivação, trabalho e outras causas, sendo que o motivo da volta aos estudos, sinalizado por grande parte, foi a necessidade do mercado de trabalho, que se encontra cada vez mais exigente em relação à capacitação e grau de estudos, sobre o qual o Parecer CNE/CEB no 4/98 reza que: No século que avizinha-se, e que está sendo chamado de "o século do conhecimento", mais e mais saberes aliados a competências tornar-se-ão indispensáveis para a vida cidadã e para o mundo do trabalho (BRASIL, 2000, p. 8).

As principais causas da evasão escolar dos alunos entrevistados foram: a necessidade de trabalhar para ajudar a família, longa distância da escola até a residência, gravidez na adolescência e falta de interesse. Vários desejam dominar a leitura para ler e entender a Bíblia. Trabalham nas mais diversas atividades, tais como vendedores ambulantes, faxineiras, babás, pedreiros, colheitas, hortas, sendo uma minoria aposentados ou pensionistas. Chegam constantemente atrasados por causa do trabalho e faltam ou evadem-se na época da colheita do café.

Ana foi a entrevistada que relatou uma infância das mais adequadas em relação a contextos familiares, acesso ao mundo letrado, metodologia dos professores, materiais utilizados, gostava de ler, mas algo aconteceu no meio desse processo, já que na quinta série, finalizando o ensino fundamental I, Ana parou de gostar de ler, desmotivou para os estudos e desistiu da escola. Quando perguntada o porquê de ter parado de gostar de ler, Ana responde: “Às vezes eu gostava e às vezes não (risadas). [...] Porque às vezes a professora pegava no pé, era chato" (ANA).

O estudo e a leitura, de que Ana gostava, tornaram-se chatos, desmotivadores, sendo que essa desmotivação foi uma das causas mais identificadas para o abandono escolar dos entrevistados. Quatro deles pararam de estudar alegando desmotivação.

A hipótese de que "A história de vida de estudantes da EJA demarca que vivenciaram poucas experiências de leitura em seus anos iniciais de estudo, escolares e extraescolares" confirma-se, principalmente, em relação ao período anterior a entrada no mundo letrado e mesmo após a aquisição da leitura, tendo em vista que a maioria deles só tinha acesso aos livros didáticos no ambiente escolar, havendo o déficit de leitura de diferentes tipos e gêneros textuais, tão importantes para adquirirem a base necessária à compreensão de leituras futuras. 
Apesar de que, as dificuldades de leitura não são consequências apenas desses fatores, dado que existem diversos outros, tais como, a questão da capacidade cognitiva geral, manipulação de fonemas, memória fonológica, capacidade verbal, déficits no processamento auditivo geral.

Conforme relatado por Snowling e Hulme (2013), o conhecimento dos nomes das letras também é responsável pela aquisição da leitura, pois no início da escola influi no desempenho futuro da leitura, haja vista que as crianças que são cercadas por textos escritos familiarizam-se com as letras como símbolos para os sons, e o reconhecimento das letras é o ponto de entrada para a aquisição da leitura, sendo que o acesso a esses textos pode dar-se tanto no ambiente escolar como em casa.

Todos os alunos, participantes da pesquisa, conseguem decodificar, adquiriram a primeira etapa da leitura, mas não compreendem o texto, apresentando déficits nas habilidades linguísticas superiores, como a capacidade de fazer inferências, o que prejudica a compreensão leitora, tendo em vista que, conforme Snowling e Hulme (2013, p. 239), a compreensão exige inferências e as inferências exigem conhecimento, os quais dificilmente adquire-se sem leituras anteriores, contato com textos diversificados.

Entende-se que, conforme Snowling e Hulme (2013, p. 265), “A capacidade geral de compreensão da leitura e seus componentes aumentam com a experiência em leitura", bem como, ainda segundo os autores, a compreensão textual é um processo complexo que exige o envolvimento de muitos componentes diferentes, entretanto, processos ativos estratégicos devem compensar a falta de estruturas de recuperação que tornam a compreensão fácil para o especialista (Ibid, p. 243).

Dessa forma, a partir da análise dos dados da pesquisa, confirma-se a hipótese de que, o pouco acesso às leituras no decorrer dos estudos, tanto na escola como fora dela, levaram esses alunos a não adquirirem os conhecimentos necessários para fazer as inferências no processo de leitura, bem como, infere-se que as estratégias de leitura não lhe foram e nem estão sendo ensinadas nas séries atuais e a leitura de gêneros diversificados vem sendo pouco utilizada e incentivada, dificultando a reversão do quadro de dificuldades, declarados pelos alunos. 


\section{Considerações finais}

A pesquisa narrativa realizada com os alunos da EJA levou-nos a refletir sobre a necessidade de uma abordagem diferenciada em sala de aula para essa modalidade, não apenas em decorrências da idade dos mesmos, como também em respeito às experiências de vida pelas quais passaram e todas as dificuldades enfrentadas e que continuam a enfrentar para fazerem parte de um ambiente letrado.

As experiências de vida desses alunos não devem ser ignoradas, dessa forma o desenvolvimento do presente estudo possibilitou uma análise de 10 entrevistas de alunos da modalidade Educação de Jovens e adultos, tempo II, que corresponde ao ensino fundamental II da educação básica, devidamente matriculados em uma escola pública do município de Itabela. Os dados coletados, através das narrativas de vida, permitiram que se fizesse uma análise comparativa com base nos contextos escolares e familiares em relação às práticas leitoras desses estudantes voluntários, bem como seu contato com o mundo dos textos orais e escritos, tanto no ambiente escolar como no familiar.

A utilização da pesquisa narrativa para a produção de dados em pesquisa proporcionou a oportunidade de vivenciar e interpretar a realidade dos alunos voluntários, suas memórias, suas experiências de vida educacionais, demarcando, nos dados transcritos, a presença e/ou ausências de práticas leitoras, constantes ou não em suas vidas, fazendo assim uma sistemática entre os presentes relatos.

O recurso de gravação das entrevistas, em áudio, mostrou-se muito prático e apropriado por permitir captar todos os detalhes da fala dos entrevistados, os sentidos de forma mais clara, reduzindo os erros de interpretação. Verificou-se que a gravação em áudio permite uma maior proximidade entre pesquisador e participantes, por não haver a preocupação, naquele momento, com a escrita da fala, além do que, o entrevistado pode deixar fluir suas memórias, fazer pausas, pensar em voz alta, suspirar, hesitar, sendo todos esses detalhes detectados na gravação e de grande utilidade para a análise dos dados.

Algumas pesquisas já foram realizadas utilizando narrativas de vida com turmas da EJA e a atual não esgota o tema, pois, tendo em vista o tempo 
curto, não pudemos realizar estudos mais aprofundados. Dada a importância do tema, espera-se que este trabalho possa contribuir para pesquisas futuras.

Por fim, tendo em vista que a compreensão exige inferências, e as inferências conhecimento, o qual dificilmente adquire-se sem leituras anteriores, contato com textos diversificados, conclui-se que, devido ao pouco acesso às leituras no decorrer dos estudos, tanto na escola como fora dela, esses alunos não adquiriram os conhecimentos necessários para fazer as inferências no processo de leitura, que levam à compreensão leitora, bem como, com base nos relatos, atualmente, poucas estratégias vem sendo utilizada para reverter esse quadro.

\section{Referências}

ABRAHÃO. Maria Helena Menna Barreto. Narrativas autorreferentes como fontes relevantes na construcão de histórias de vida. Pontifícia Universidade Católica Do Rio Grande Do Sul - Pucrs, Porto Alegre, RS, Brasil, 2011. Disponível em: $\quad<$ http://www.sbhe.org.br/novo/congressos/cbhe6 /anais_vi_cbhe/conteudo/file/918.pdf>. Acesso em: jan./2017.

BENJAMIN, Walter. Obras escolhidas. Magia e técnica, arte e política. 7a ed., São Paulo: Brasiliense, 1994.

CONSENZA, Ramon M. Neurociência e educação: como o cérebro aprende. Porto Alegre: Artmed, 2011.

FREIRE, Paulo. A importância do ato de ler: em três artigos que se completam. São Paulo: Autores Associados: Cortez, 1989.

FREIRE, Paulo. Pedagogia da Autonomia: Saberes necessários à prática educativa, Editora Paz e Terra, 1996.

GIBBS, Graham. Análise de dados qualitativos. Artmed editora S.A. Porto Alegre - RS, 2009.

LEITE, Sérgio Antônio da Silva. Afetividade e letramento na educação de jovens e adultos EJA. São Paulo: Cortez, 2013.

MONTEIRO, Rebecca de Magalhães; SANTOS, Acácia Aparecida Angeli Santos. Recursos familiares e desempenho de crianças em compreensão de leitura. Psico, Porto Alegre, PUCRS, v. 44, n. 2, pp - 273 - 279, abr./jun. 2013.

MORAN, José Manuel. Novas tecnologias e mediação pedagógica. Campinas, SP: Papirus, 2000.

POLONIA, Ana da Costa; DESSEN, Maria Auxiliadora. Em busca de uma compreensão das relações entre família e escola. Psicologia Escolar e Educacional, 2005. Vol. 9, nr. 2, p. 3030-312. 
SABINO, Maria Manuela do Carmo de. Importância educacional da leitura e estratégia para a sua promoção. Revista Iberoamericana de Educación, no 45/5 - 25 de março de 2008.

SANTOS, Maria Meneses dos; SANTOS, Rosangela da Silva. A etapa de análise no método história de vida: Uma experiência de pesquisadores de enfermagem. Florianópolis, 2008.

SILVA, Arlete Vieira da. O Gênero memorial na pesquisa (auto) biográfica: Concepcões e percursos metodológicos. In: SOUZA, Elizeu Clementino de. (Auto) biografias e documentação narrativa: redes de pesquisa e formação. Salvador: EDUFBA, 2015 a.

SILVEIRA, Maria Inez Matoso. Modelos teóricos e estratégias de leitura: suas implicações no ensino. Maceió: EDUFAL, 2005.

SNOWLING, Margaret J.; HULME, Charles (Org.). A ciência da leitura. Porto Alegre: Penso, 2013.

SOUZA, Linete Oliveira de; BERNARDINO, Andreza Dalla. A contação de histórias como estratégia pedagógica na educação infantil e ensino fundamental. Educere et Edicare. Revista de Educação. Vol. 6 no12. Jul./dez. 2011. p. 235-249.

TORRES, Shirlei Milene; TETTAMANZY, Ana Lúcia Liberato. Contação de histórias: resgate da memória e estímulo à imaginação. Revista eletrônica de crítica e teoria de literaturas. Sessão aberta. PPG-LET-UFRGS - Porto Alegre vol. 04 N. 01 - jan./jun. 2008.

Recebido em 29 de abril de 2019.

Aceito em 30 de maio de 2019. 